\title{
Improving nurse-physician teamwork through interprofessional bedside rounding
}

This article was published in the following Dove Press journal:

Journal of Multidisciplinary Healthcare

2 May 2016

Number of times this article has been viewed

\author{
Stanislav Henkin' \\ Tony Y Chon ${ }^{2}$ \\ Marie L Christopherson ${ }^{3}$ \\ Andrew J Halvorsen ${ }^{1,4}$ \\ Lindsey M Worden ${ }^{3}$ \\ John T Ratelle ${ }^{5}$ \\ 'Department of Medicine, Mayo \\ Clinic, ${ }^{2}$ Division of General Internal \\ Medicine, Mayo Clinic, ${ }^{3}$ Department of \\ Nursing, Mayo Clinic, ${ }^{4}$ Department of \\ Medicine, Internal Medicine Residency \\ Office of Educational Innovations, \\ Mayo Clinic, ${ }^{5}$ Division of Hospital \\ Medicine, Mayo Clinic, Rochester, \\ MN, USA
}

Correspondence: John T Ratelle Division of Hospital Medicine, Mayo Clinic, 200 First Street SW, Rochester, MN 55905, USA

Tel + I 5072933589

Email Ratelle.John@mayo.edu
Background: Teamwork between physicians and nurses has a positive association with patient satisfaction and outcomes, but perceptions of physician-nurse teamwork are often suboptimal. Objective: To improve nurse-physician teamwork in a general medicine inpatient teaching unit by increasing face-to-face communication through interprofessional bedside rounds.

Intervention: From July 2013 through October 2013, physicians (attendings and residents) and nurses from four general medicine teams in a single nursing unit participated in bedside rounding, which involved the inclusion of nurses in morning rounds with the medicine teams at the patients' bedside. Based on stakeholder analysis and feedback, a checklist for key patient care issues was created and utilized during bedside rounds.

Assessment: To assess the effect of bedside rounding on nurse-physician teamwork, a survey of selected items from the Safety Attitudes Questionnaire (SAQ) was administered to participants before and after the implementation of bedside rounds. The number of pages to the general medicine teams was also measured as a marker of physician-nurse communication.

Results: Participation rate in bedside rounds across the four medicine teams was $58 \%$. SAQ response rates for attendings, residents, and nurses were 36/36 (100\%), 73/73 (100\%), and 32/73 (44\%) prior to implementation of bedside rounding and 36 attendings (100\%), 72 residents $(100 \%)$, and $14(19 \%)$ nurses after the implementation of bedside rounding, respectively. Prior to bedside rounding, nurses provided lower teamwork ratings (percent agree) than residents and attendings on all SAQ items; but after the intervention, the difference remained significant only on SAQ item 2 ("In this clinical area, it is not difficult to speak up if I perceive a problem with patient care", $64 \%$ for nurses vs $79 \%$ for residents vs $94 \%$ for attendings, $P=0.02$ ). Also, resident responses improved on SAQ item 1 ("Nurse input is well received in this area", $62 \%$ vs $82 \%, P=0.01$ ).

Conclusion: Increasing face-to-face communication through interprofessional bedside rounding can improve the perceptions of nurse-physician teamwork, particularly among residents and nurses.

Keywords: interprofessional care, teamwork, graduate medical education, hospital medicine

\section{Introduction}

Collaboration between physicians and nurses is essential for providing quality health care, and breakdown in this area is a major root cause of sentinel events. ${ }^{1}$ Indeed, improved perceptions of nurse-physician teamwork have been shown to be associated with higher satisfaction and better outcomes among hospitalized patients. ${ }^{2-5}$ Despite its importance, however, research has shown that teamwork between nurses and physicians is often suboptimal. ${ }^{6-8}$ Fortunately, structured interventions aimed to improve

submit your manuscript | www.dovepress.con 
teamwork between nurses and physicians can succeed and have been shown to have a positive impact on teamwork and patient outcomes. $^{9-11}$ Specifically, creating a system to involve nurses and physicians in rounds at the patient's bedside can help create a shared mental model and increase collaborative activities. ${ }^{12}$

To improve the culture of teamwork on a general medical teaching unit at our institution, we designed a quality improvement (QI) project that incorporated nurses into daily bedside morning rounds with the physician team.

\section{Methods}

This QI project involved collaboration of physicians (both internal medicine residents and attendings) and nurses from four general medicine services on one 36-bed nursing unit of Mayo Clinic Hospital - Saint Mary's Campus, Rochester, MN. Each general medicine service comprises three interns, one senior resident, and one attending physician. Residents rotate on the service in 4- or 5-week blocks, and attendings rotate in 2-week blocks.

In the spring of 2013, an interprofessional workshop was held to identify the barriers and opportunities for improving nurse-physician teamwork. The lack of face-to-face interaction on daily rounds was identified as a frequent source of communication breakdown and dissatisfaction. To address this gap, a formal process for interprofessional bedside rounding (IBR) was created. During IBR, each general medicine team would notify a patient's nurse, through alphanumeric paging, when the team was rounding on that patient, so the nurse would meet the team at the patient's bedside. This allowed for direct communication between the nurse and physician team, such that they were able to participate in rounds collaboratively.
IBR was piloted in small Plan-Do-Study-Act cycles during June 2013 with direct feedback solicited from participating nurses and physicians. Early responses to the pilot indicated that IBR interactions were frequently unstructured, and this sometimes led to ineffective communication. To address this barrier, a rounding "checklist" (Figure 1) was created and utilized by the nurse during IBR to ensure that key issues were addressed. The content of the checklist was derived from feedback of physician and nurse participants and input from the QI leadership team and included key patient care-related issues. Daily audits were performed by the charge nurse to assess the rates of participation. IBR was fully implemented on all the medicine teams at the start of the academic year in July 2013.

To measure the impact of IBR on nurse-physician teamwork, we used the teamwork climate items from the Safety Attitudes Questionnaire (SAQ) short form. ${ }^{13}$ The SAQ is a teamwork assessment tool scored on a 5-point Likert scale (1, strongly disagree; 3 , neutral; 5, strongly agree). ${ }^{14}$ The SAQ has been shown to be reliable with known internal structure, criterion, and outcomes validity, and the teamwork climate items have been used in previous research regarding nurse-physician teamwork in a medical inpatient setting. ${ }^{15,16}$ Responses were solicited from 36 attendings, 73 residents, and 73 nurses before (May 2013) and 36 attendings, 72 residents, and 73 nurses after (October 2013) the intervention. To encourage participation in the project, surveys from physicians and nurses were submitted anonymously, and responses were not linked to demographic information such as age, sex, or years of experience.

Given their ordinal nature, the SAQ responses of strongly agree and agree were combined into "agree", and the responses neutral, disagree, and strongly disagree were combined into "do not agree" for analysis. The number (percentage) of those who responded agree was reported by

\begin{tabular}{|l|l|}
\hline Daily checklist: to be utilized by bedside RN and discussed during bedside rounds & \\
\hline Updates from nights: & \\
\hline Vital signs: trends, baseline versus current, weights & \\
\hline Pain: & \\
\hline Safety concerns: activity, PT/OT, safety eval needed & \\
\hline Cognition: baseline versus current & \\
\hline Respiratory: wean $\mathrm{O}_{2}$, home $\mathrm{O}_{2}$, new rx, nebulizer/inhaler needs & \\
\hline Wounds, drains, tubes: pressure ulcers, wound care & \\
\hline Nutrition/hydration: fluids, intake, current/future diet orders, NPO for tests, nausea & \\
\hline Elimination: diarrhea, constipation, urinary retention, incontinence & \\
\hline Plan: for the day/stay, tests, consults, anticipated discharge date/needs, education needs & \\
\hline Questions from patient/family: & \\
\hline
\end{tabular}

Figure I Interprofessional bedside rounding checklist.

Abbreviations: RN, registered nurse; PT, physical therapy; OT, occupational therapy; rx, prescription; NPO, nil per os; eval, evaluation. 
group for each SAQ item. Within-group and between-group survey responses were compared using Fischer's exact tests.

As an additional measurement of the effect of IBR on nurse-physician communication, the total number of pages to the medicine service pagers (adjusted for patient census) was collected over a 30-day period before and after implementation of IBR and assessed using a Wilcoxon rank sum test.

According to the policy activities that constitute research at the Mayo Clinic, this study met the criteria for QI activities exempt from ethics review.

\section{Results}

SAQ responses were available from all (100\%) attendings and residents before and after IBR, along with those from 32 nurses (44\%) pre-IBR and 14 nurses (19\%) post-IBR (Table 1). Average participation in IBR, defined as occurring when the physician team and nurse met at the patient's bedside to discuss the plan of care, across all four medicine services during the QI project was 58\%.

Within-group comparisons showed that after the implementation of IBR, resident agreement significantly improved on SAQ item 1 ("Nurse input is well received in this area", $62 \%$ vs $82 \%, P=0.01)$. Between-group comparisons showed that prior to IBR, a significant difference existed between the nurses, residents, and attendings for all six SAQ items (Table 1), with nurses generally indicating lower SAQ responses than residents and attendings. Post-IBR, the differ- ences in agreement between nurses, residents, and attendings remained significant only on SAQ item 2 ("In this clinical area, it is not difficult to speak up if I perceive a problem with patient care", $64 \%$ vs $79 \%$ vs $94 \%, P=0.02$ ).

Analysis of pages to the medicine service pagers revealed that after the implementation of IBR, there was a trend toward decreased number of pages per patient per day (7.5 vs 6.9, $P=0.08)$.

\section{Discussion}

To our knowledge, this project is the first to assess the impact of IBR on nurse-physician teamwork in an internal medicine teaching unit. We found that the implementation of IBR led to improvement in several domains of teamwork between nurses and physicians. Our findings have implications for nursing and physician hospital administrators, as they attempt to improve interprofessional collaboration in inpatient medical units.

The positive effects of bedside interprofessional collaboration have been shown in other hospital practice settings such as obstetrics ${ }^{17}$ and the intensive care unit. ${ }^{10}$ As it relates to medical units specifically, our findings build upon the work of Sharma and Klocke, ${ }^{18}$ who evaluated the effect of IBR on a hospitalist unit and found similar improvement in perceptions of teamwork among nurses. In addition to teamwork perceptions, we also found a trend toward a reduction in page volumes to physicians by nurses, although this did not reach statistical significance. However, previous literature

Table I Attendings, residents, and nurses Safety Attitude Questionnaire responses before and after the implementation of interprofessional bedside rounds

\begin{tabular}{|c|c|c|c|c|c|c|c|c|}
\hline \multirow[b]{2}{*}{ Teamwork item } & & \multicolumn{2}{|c|}{ Nurse } & \multicolumn{2}{|c|}{ Resident } & \multicolumn{2}{|c|}{ Attending } & \multirow[b]{2}{*}{ P-value* } \\
\hline & & $\mathbf{n}$ & Agree (\%) & $\mathbf{n}$ & Agree (\%) & $\mathbf{n}$ & Agree (\%) & \\
\hline \multirow{3}{*}{$\begin{array}{l}\text { Item I: Nurse input is well received in } \\
\text { this area }\end{array}$} & Pre-IBR & 32 & $18(56)$ & 73 & $45(62)$ & 36 & $30(83)$ & 0.03 \\
\hline & Post-IBR & 14 & $10(7 \mathrm{I})$ & 72 & $59(82)$ & 36 & $30(83)$ & 0.63 \\
\hline & P-value* & & 0.51 & & 0.01 & & $>0.99$ & \\
\hline Item 2: In this clinical area, it is not difficult & Pre-IBR & 32 & II (34) & 73 & $54(74)$ & 36 & $35(97)$ & $<0.0001$ \\
\hline to speak up if I perceive a problem with & Post-IBR & 14 & $9(64)$ & 72 & $57(79)$ & 36 & $34(94)$ & 0.02 \\
\hline patient care & P-value* & & 0.10 & & 0.56 & & $>0.99$ & \\
\hline Item 3: The physicians and nurses here & Pre-IBR & 32 & $10(3 \mathrm{I})$ & 73 & $43(59)$ & 36 & $26(72)$ & 0.003 \\
\hline work together as a well-coordinated & Post-IBR & 14 & $7(50)$ & 72 & $47(65)$ & 36 & $28(78)$ & 0.15 \\
\hline team & $P$-value* & & 0.32 & & 0.49 & & 0.79 & \\
\hline \multirow{3}{*}{$\begin{array}{l}\text { Item 4: Disagreements in this clinical } \\
\text { area are resolved appropriately }\end{array}$} & Pre-IBR & 32 & $17(53)$ & 73 & $50(69)$ & 36 & $33(94)$ & 0.0003 \\
\hline & Post-IBR & 14 & $10(7 I)$ & 72 & $49(69)$ & 36 & $31(86)$ & 0.14 \\
\hline & P-value* & & 0.34 & & $>0.99$ & & 0.43 & \\
\hline Item 5: It is easy for personnel here to & Pre-IBR & 32 & $24(75)$ & 73 & $51(70)$ & 36 & $32(91)$ & 0.04 \\
\hline ask questions when there is something & Post-IBR & 14 & $13(93)$ & 72 & $56(78)$ & 36 & $32(89)$ & 0.27 \\
\hline that they do not understand & P-value* & & 0.24 & & 0.35 & & $>0.99$ & \\
\hline \multirow{3}{*}{$\begin{array}{l}\text { Item 6: I have the support I need from } \\
\text { other personnel to care for patients }\end{array}$} & Pre-IBR & 32 & $25(78)$ & 73 & $50(68)$ & 36 & $31(9 \mid)$ & 0.03 \\
\hline & Post-IBR & 14 & I I (79) & 72 & $58(8 I)$ & 36 & $34(94)$ & 0.13 \\
\hline & P-value* & & $>0.99$ & & 0.13 & & 0.67 & \\
\hline
\end{tabular}

Notes: Agree $=$ strongly agree + agree; *Fischer's exact test.

Abbreviation: IBR, interprofessional bedside rounding. 
has shown that the effect of interventions on communication practices can be complex and difficult to predict and should be a focus of future research. ${ }^{19}$

Baseline attitudinal discrepancies regarding teamwork existed between providers, with physicians giving higher ratings than nurses. Similar findings have been shown in previous research of medical ${ }^{16}$ and nonmedical units, ${ }^{20}$ and high baseline perceptions of teamwork by physicians may explain why we did not find a significant improvement in SAQ scores of attendings after implementation of IBR. The reason for the difference in teamwork perceptions is likely multifactorial and may, in part, be related to hierarchical differences between physicians and nurses in the decisionmaking process. ${ }^{21,22}$ Further research is required to better understand these discrepant perceptions.

While we have shown that IBR appears to have a positive impact on nurse-physician teamwork, our project has limitations. SAQ responses were not linked to demographic data and were submitted anonymously, and therefore, they could not be paired for analysis. Response rates from nursing staff were lower than from residents and attendings, which likely limited the power with which to detect a significant improvement in SAQ scores for that group. This difference in response rate may have been due to difference in survey administration methods, as physicians were surveyed electronically, while nursing staff provided paper surveys.

The participation rate in IBR was consistently lower than our predetermined goal, which brings into question its sustainability, but our rates are similar to those of previous studies on IBR. ${ }^{23}$ Currently, we are working to overcome this barrier by promoting the use of a white board in the patient's room, which contains prompts and space to write similar information to that outlined in the checklist. It can be updated by the physician team or nursing staff to allow for asynchronous communication, when IBR is not possible. Future steps in this will aim to promote sustainability and generalizability to other units and hospitals.

\section{Conclusion}

In summary, improving physician-nurse collaboration through IBR can positively impact perceptions of teamwork. Further work is required to understand the impact of IBR on patient satisfaction and outcomes.

\section{Acknowledgment}

This work was presented in poster form at Minnesota American College of Physicians on November 8, 2013 and in oral form at National American College of Physicians on April 11, 2014.

\section{Disclosure}

The authors report no conflicts of interest in this work.

\section{References}

1. Sentinel Event Data Root Causes by Event Type 2004-2015. Available from: http://www.jointcommission.org/assets/1/18/Root_Causes_by_ Event_Type_2004-2015.pdf. Accessed February 17, 2016.

2. Baggs JG, Schmitt MH, Mushlin AI, et al. Association between nursephysician collaboration and patient outcomes in three intensive care units. Crit Care Med. 1999;27(9):1991-1998.

3. Meterko M, Mohr DC, Young GJ. Teamwork culture and patient satisfaction in hospitals. Med Care. 2004;42(5):492-498.

4. Schmitt MH. Collaboration improves the quality of care: methodological challenges and evidence from US health care research. $J$ Interprof Care. 2001;15(1):47-66.

5. Davenport DL, Henderson WG, Mosca CL, Khuri SF, Mentzer RM Jr. Risk-adjusted morbidity in teaching hospitals correlates with reported levels of communication and collaboration on surgical teams but not with scale measures of teamwork climate, safety climate, or working conditions. J Am Coll Surg. 2007;205(6):778-784.

6. Thomas EJ, Sexton JB, Helmreich RL. Discrepant attitudes about teamwork among critical care nurses and physicians. Crit Care Med. 2003;31(3):956-959.

7. Nair DM, Fitzpatrick JJ, McNulty R, Click ER, Glembocki MM. Frequency of nurse-physician collaborative behaviors in an acute care hospital. J Interprof Care. 2012;26(2):115-120.

8. O’Leary K, Ritter C, Wheeler H, Szekendi M, Brinton T, Williams M. Teamwork on inpatient medical units: assessing attitudes and barriers. Qual Saf Health Care. 2010;19(2): 117-121.

9. O'Leary KJ, Buck R, Fligiel HM, et al. Structured interdisciplinary rounds in a medical teaching unit: improving patient safety. Arch Intern Med. 2011;171(7):678-684.

10. Narasimhan M, Eisen LA, Mahoney CD, Acerra FL, Rosen MJ. Improving nurse-physician communication and satisfaction in the intensive care unit with a daily goals worksheet. Am J Crit Care. 2006;15(2):217-222.

11. Zwarenstein M, Goldman J, Reeves S. Interprofessional collaboration: effects of practice-based interventions on professional practice and healthcare outcomes. Cochrane Database Syst Rev. 2009(3):CD000072.

12. McComb SA, Henneman EA, Hinchey KT, et al. Improving teamwork on general medical units: when teams do not work face-to-face. $J t$ Comm J Qual Patient Saf. 2012;38(10):471-478.

13. Safety Attitudes: Frontline Perspectives from this Patient Care Area. Available from: https://med.uth.edu/chqs/files/2012/05/SAQ-ShortForm-2006.pdf.

14. Sexton JB, Helmreich RL, Neilands TB, et al. The Safety Attitudes Questionnaire: psychometric properties, benchmarking data, and emerging research. BMC Health Serv Res. 2006;6:44.

15. Havyer RD, Wingo MT, Comfere NI, et al. Teamwork assessment in internal medicine: a systematic review of validity evidence and outcomes. J Gen Intern Med. 2014;29(6):894-910.

16. O'Leary KJ, Wayne DB, Haviley C, Slade ME, Lee J, Williams MV. Improving teamwork: impact of structured interdisciplinary rounds on a medical teaching unit. J Gen Intern Med. 2010;25(8):826-832.

17. Baldwin M, Hashima J, Guise JM, Gregory WT, Edelman A, Segel S. Patient-centered collaborative care: the impact of a new approach to postpartum rounds on residents' perception of their work environment. J Grad Med Educ. 2010;2(1):62-66.

18. Sharma U, Klocke D. Attitudes of nursing staff toward interprofessional in-patient-centered rounding. J Interprof Care. 2014;28(5):475-477.

19. Quan SD, Wu RC, Rossos PG, et al. It's not about pager replacement: an in-depth look at the interprofessional nature of communication in healthcare. J Hosp Med. 2013;8(3):137-143. 
20. Adler-Milstein J, Neal K, Howell MD. Residents' and nurses' perceptions of team function in the medical intensive care unit. J Crit Care. 2011;26(1):104.e7-115.e7.

21. Zwarenstein M, Rice K, Gotlib-Conn L, Kenaszchuk C, Reeves S. Disengaged: a qualitative study of communication and collaboration between physicians and other professions on general internal medicine wards. BMC Health Serv Res. 2013;13:494.
22. Gotlib Conn L, Reeves S, Dainty K, Kenaszchuk C, Zwarenstein M. Interprofessional communication with hospitalist and consultant physicians in general internal medicine: a qualitative study. BMC Health Serv Res. 2012;12:437.

23. O'Leary KJ, Killarney A, Hansen LO, et al. Effect of patient-centred bedside rounds on hospitalised patients' decision control, activation and satisfaction with care. BMJ Qual Saf. Epub 2015 Dec 1.
Journal of Multidisciplinary Healthcare

\section{Publish your work in this journal}

The Journal of Multidisciplinary Healthcare is an international, peerreviewed open-access journal that aims to represent and publish research in healthcare areas delivered by practitioners of different disciplines. This includes studies and reviews conducted by multidisciplinary teams as well as research which evaluates the results or conduct of such teams or health-

\section{Dovepress}

care processes in general. The journal covers a very wide range of areas and welcomes submissions from practitioners at all levels, from all over the world. The manuscript management system is completely online and includes a very quick and fair peer-review system. Visit http://www.dovepress.com/ testimonials.php to read real quotes from published authors.

Submit your manuscript here: https://www.dovepress.com/journal-of-multidisciplinary-healthcare-journal 